\title{
Leadership Needs and Development Framework: An Empirical Study of Third-Line Leaders in the Kuwait Oil and Gas Sector.
}

\author{
Dr. Alawi Taqi \\ Practitioner in Leadership Position \\ Kuwait Oil Industry \\ Dr. Ameen Talib \\ Head of Applied Projects \\ The School of Business, Singapore \\ University of Social Sciences, Singapore
}

\begin{abstract}
This paper analyses the 'needs', 'skills' and 'capabilities' development of third-line leaders working in the Kuwait's Oil and Gas Sector companies. Leadership has been widely studied yet little understood about third line leaders in developing countries such as Kuwait. They have the responsibility of converting the task from plan into reality. This paper looked at the "team leader" or "third-line leaders" in the Kuwait's oil and gas sector. Empirical data was collected from 42 third-line leaders via personal in-depth interviews. The findings indicated gaps in the effectiveness of leadership development. A framework is proposed that stresses on the importance of identifying needs of leaders in relation to contextual factors to achieve leadership development. This leads to leadership behaviours and capabilities that will produce effective leadership.
\end{abstract}

Keywords: Leadership, Third-line leaders, Kuwait, Oil and Gas.

Leadership Needs and Development Framework: An Empirical Study of Third-Line Leaders in the Kuwait Oil and Gas Sector.

\section{1: Introduction}

A review of the literature shows lack of studies in Kuwait on third-line leadership in the oil and gas sector. Even in other countries where leadership studies have been carried out, the focus has been largely on middle and top leadership positions and not on the lower leadership positions (third-line leaders). This study contributes to the literature on distributed leadership is important towards the understanding of leadership effectiveness of third-line leaders within the Oil and Gas Sector of Kuwait.

There are several leadership theories, but few provide any long-term solutions to the needs of third-line leaders. Whilst the different leadership approaches have their own strengths, they also have their limitations. These limitations have partly given rise to the evolution of leadership studies with the view to explain leader behaviours and effectiveness. Furthermore, whilst these theories have contributed to an understanding of leadership, no specific theory to date offers specific explanations to third-line leadership (Overby and Suvanujasiri, 2012).

This paper recommends framework for the Kuwait oil and gas sector that links leadership needs, skills and capabilities specific to the sector. The framework can also be extended to other business environments to study leadership based on the contextual factors. Kuwait is a relatively small country, with only about 1.4 million Kuwaitis who constitute about one-third of the country's residents of almost 4 million. This means that the country must rely on foreign manpower.

Kuwait oil and gas sector are completely owned and operated by the government. The Kuwait oil and gas sector has several entities and all of them come under the umbrella of the Kuwait Petroleum Corporation (KPC). The sector has a Supreme Petroleum Council (SPC) that oversees all activities related to this sector.The Oil and Gas Sector is a highly technical area that requires special skills, which must be imparted through various forms of training and development. Furthermore, Kuwait is a collectivist society. It is thus important to note that a penchant for 'in-group collectivism' is a defining element of leadership in Kuwait along with other Middle Eastern countries (Northouse, 2013). Therefore, leadership development needs to be specific to the sector and the culture of the country. 


\section{2: Literature Review}

Leadership development in this study is viewed as intervention processes that seek to expand a person's capacity to be effective in leadership roles. Leadership development can thus be viewed as expanding the collective capacity of organisational members to engage effectively in leadership roles and processes in anticipation of unforeseen challenges and across a wide range of situations (Bolden, 2004; 2005; Burgoyne et al., 2004).

According to Bass and Stogdill (1990) "Leadership is an interaction between two or more members of a group that often involves a structuring or restructuring of the situation and the perceptions and expectations of the members. Leaders are agents of change-persons whose acts affect other people more than other people's acts affect them. Leadership occurs when one group member modifies the motivation or competencies of others in the group" (cited in Okoji, 2014; p. 84-85).

Leadership development is dominated by individualistic approaches that seek to enhance the intrapersonal attributes, interpersonal qualities, cognitive abilities, communication skills and task-specific skills of individual participants (Bolden 2010). The core components of leadership development include skill-building, personal growth and feedback approaches as the core mainstream components(Clarke 2012).Successful leadership development consists of refining teachable goals, improving the abilities of the leaders, tapping individuals' personal needs, interests, and self-esteem, and, helping managers see and move beyond their interpersonal blocks. Therefore, leadership development should be concentrated on their individual needs and organizational processes (Clarke 2012).

Oil companies worldwide tend to be large because of the diversity of activities involved, such as oil exploration, rigging, exploration, piping, refining, marketing and shipping. As such, it may not be possible for the person at the helm of the organisation to think for the whole organisation (Senge, 2006), and instead visionary initiative is needed throughout (Sosik and Dinger, 2007). As a result, great emphasis is being placed on individuals throughout the organisation to take a leadership role (Senge, 2006), even in relatively small, lower-level, and/or informal organisational spheres, which gives credence to the distributed leadership paradigm.

Distributed leadership acknowledges that leadership is comprised of a collection of behaviours that can be rotated among the members of the group (DeChurch et al., 2010). The strength in distributed leadership lies in the fact that team members may bring diverse skills and expertise to the table, which is an important precondition to the selective emergence of different individuals into the leadership role, failure of which there is no reason for different individuals to take on different aspects of the leadership role at different times (Friedrich et al., 2009). Distributed leadership highlights the importance of other leaders in an organisation taking on other different elements of a leadership role as opposed to the person at the helm of the organisation. This is a central tenet of distributed leadership, which may lead to overall team effectiveness through cooperation and coordinated action by multiple leaders with overlapping but different responsibilities (Gronn, 2002; Yukl, 2013).

However, in Arab countries such as Kuwait, even when followers were recognized as part of a process (such as in the leader member exchange (LMX), followers have seldom been considered to be true partners in leadership to the extent that they would actually be responsible for making some leadership decisions and assessments. If anything, when subordinates were considered in achieving leadership roles, there are chances of higher threat due to 'emergent' leadership characteristics (Mameli, 2013).

\section{3: Methodology}

This research has collected primary data from the third-line managers in the oil and gas sector. This was done through personal in-depth interviews. The interviews were carried out in the respective third-line leaders' office.

During the time of the interview, there were 42 third-line leaders in the oil and gas sector and each of them were contacted and appointments for interviews were fixed. The interviews took around two hours per individual. The interviews were voice recorded (with permission) and transcribed into a 500-page document, which lead to the discussion of the findings.

The researcher has been working in the oil and gas sector for decades and therefore knew several of the third-line leaders. Based on this, an open relationship between the researcher and the respondents was established. This helped in the respondents speaking freely about their current work scenario and answering the questions to the best of their ability.

Interpretivist/constructivist approaches to research have the intention of understanding "the world of human experience" (Cohen \& Manion, 1994, p. 36), suggesting that "reality is socially constructed" (Mertens, 2005, p. 12). It is argued that the interpretivist/constructivist researcher tends to rely upon the "participants' views of the situation being studied" (Creswell, 2003, p. 8) and recognises the impact on the research of their own background 
and experiences. Creswell (2003) claim that interpretivist researchers discover reality through participant's views, their own background and experiences.

\section{4: Findings Discussion}

The interviews revealed several factors that impacts the needs and development of knowledge, skills and abilities (KSA) of third-line leaders. This section will provide the factors that have been identified, followed by the development of the recommended framework.

\subsection{Business Knowledge}

The interviewees stated the importance of extending beyond technical sophistication to include business acumen within the leadership team. This included broad understanding of financial, human resources and operational issues.

\subsection{Leadership Skills}

The interviewees raised several skills that were found to be regarded as critical to effective leadership development. These are discussed below based on the findings.

Technical Skills: A third-line leader needs to address the significant operational and technical issues and problems associated with achieving their objectives. The technical skills varied immensely from procurement, planning, legal, and marketing, finance, performance management, IT, quality management and projects management.

Leadership and managerial skills:Third-line leaders are expected to fill the roles of leading processes, e.g. coordinating with upper management, leading the team in goal setting processes, providing overall leadership for the team, supporting team members in operations, planning and site processes.

Communication skills: Kuwaitis by their very nature talk a lot amongst themselves as part of their socialisation. But such communication was not present in the workplace. The findings showed that there was lack of free flow of information amongst organisational members.

Decision-making skills: Knowing how decision flows work helps leaders leverage the flows to achieve their goals and to make changes to the decision flows that can help in achieving these goals. Information flows are critical in support of the decision-making flows and workflows because information provides the critical knowledge about internal and external factors that affect the organisation's management flows and how these flows respond to these factors.

Change management skills: Change management was an important leadership skill that was missing amongst the third-line leaders. Leaders must be adaptable to changing and challenging circumstances.

\subsection{Leadership development}

Leadership development, as a type of human development, takes place over time and tends to be incremental in nature. It is the result of complex reciprocal interactions between the leader, others, and the social environment. The elements of a full range leadership development are self-awareness and development (intrapersonal skills), social or human-relational development (interpersonal skills), and the ability to affect the context in which development is occurring (change agency).

We propose the essence of leadership development experiences lies in the interaction of the intrapersonal and the interpersonal components. Whilst the identification of key leadership needs and capabilities of third-line leaders within the Kuwait's Oil and Gas Sector was the primary focus of the research project, the specifics of how to develop such skills and capabilities was also of interest. The findings showed the need to close the gap in skill and competency between these third-line leaders and senior level leadership within the Kuwait's Oil and Gas Sector. Based on the findings, the following leadership development plans are recommended:

Action learning: It is a set of organisational development practices in which important real-time organisational problems are tackled (Johnson and Cacioppe, 2012). It represents a comprehensive way that knits together on-thejob experience, life experience, and specific skill development. It was viewed by the third-line leaders as learning from experiences that happen during day-to-day work.

Interaction and socialisation: Supportive leaders engage in relationship-building at the individual and group levels. Seeking personal knowledge of each developing third-line leader and interacting with them on a regular basis creates opportunities for feedback and coaching and a better understanding of individual growth needs.

The support of the senior manager in understanding development needs and helping arrange for stretch assignments for top talent is key to the social construction of an effective leadership development system.

Classroom-based training: Classroom-based training was an important leadership development technique recognized by the study participants. Such training is a formal instruction that is presented or developed by experts. 
Attending international conferences: Leadership, like wisdom, cannot be taught as if it was a single skill, but it requires the gaining of experience, developing the intellect, allowing reflection and increasing knowledge.

Coaching: Coaching involves practical, goal-focused forms of one-on-one learning and, ideally, behaviour change. A coaching style of leadership entailed having individual conversations with each direct report, understanding their personal career goals and needs, and offering guidance.

Self-learning: Individual development is an important part of serving the needs of the group, family, or organisation and achieving one's personal best requires investment in individual skills development. For those that manage to complete some recognised programmes, such as an MBA qualification, they are refunded the full cost of the programme on successful completion of the programme, which gives them some motivation to complete it.

Attachments: On-the-job training, feedback, and mentoring are viewed as the most important leadership development methodologies across several regions.

\section{5: Recommended Framework}

Drawing upon insights from the 42 participants from the Oil and Gas Sector of Kuwait, and the deconstruction of the interview data, several leadership needs were identified as essential elements of the framework, as reflected in figure 1. This framework has been developed and recommended for the oil and gas sector in Kuwait.

The framework in figure 1is a development of framework recommended by Bolden $(2004,2010)$ and Burgoyne et al. (2004). From a distributed leadership perspective, it is necessary to study the impact of contextual factors particularly applicable to the Kuwait oil and gas sector, from a third-line leader viewpoint, on the leadership needs, leadership development, leadership behaviours and capabilities identified in the framework (figure 1). The most important and relevant needs identified and consolidated leadership needs were business knowledge, technical skills, leadership and managerial skills, communication skills, decision-making skills and change management skills. These leadership needs reflected what the participants generally wanted (or what they personally believed in) as essential leadership needs.

Distributed leadership offered the promise of a new 'unit of analysis' through which leadership could be understood in a holistic sense rather than simply as the aggregation of individual contributions. Bolden (2011) refers to this dimension of leadership as 'concretive action' (this means, additional dynamic which is the product of conjoint activity) and illustrated his argument with three alternative forms of engagement ('spontaneous collaboration', 'intuitive working relationships' and 'institutionalized practices') each of which could be considered as a manifestation of 'conjoint agency'. Bolden (2011) calls for a fundamental reframing of leadership, suggesting that it 'is more appropriately understood as a fluid and emergent, rather than as a fixed, phenomenon' (p. 252).

This points towards seeing distributed leadership within the oil and gas industry of Kuwait - as well as other similar contexts internationally - as being explainable by revealing the interpretations of the actors from whose conjoint relationships emerges the distribution of leadership. Distributed leadership is considered as a social phenomenon with a context integral to its understanding and, indeed, constitutive of the practice of leadership, concerned with thinking and actions in situ (in its original place). The focus therefore is on conjoint actions rather than role or position. It is the way in which leading is enacted in the performance of tasks that is important (Thrope et al., 2011).

The outcome of leadership development is that these third-line leaders acquire the leadership capabilities required to perform their tasks effectively. These capabilities are complex bundles of individual talents, attitudes, skills, and accumulated knowledge exercised through organisational processes, and unique styles that enable the organisation to co-ordinate activities and make use of their resources. The leaders will be able to undertake their tasks, manage relations with their subordinates and peers as well as bring about change. One of the defining challenges for leaders is to take their organisations into the future by implementing planned organisational changes that correspond to premeditated interventions intended to modify organisational functioning towards more favourable outcomes.

The Kuwait context is characterised by hierarchical structures, in-line with its high-power distance culture (House et al., 2004), and by over-staffing and labour laws that protect Kuwaitis, along with favouritism (known in Kuwait as 'Wasta').

The Gas and Oil Sector companies are large corporations with extensive state ownership and involvement, but their structures are somewhat disjointed. These large organisations tend to have standard operating procedures, which then suit certain leadership development initiatives and not others, and the organisations tend to have more resources to devote to leadership development. These contextual factors influence how leadership is exhibited and developed and ultimately on the overall organisational performance. 
Figure 1: Leadership needs and development framework

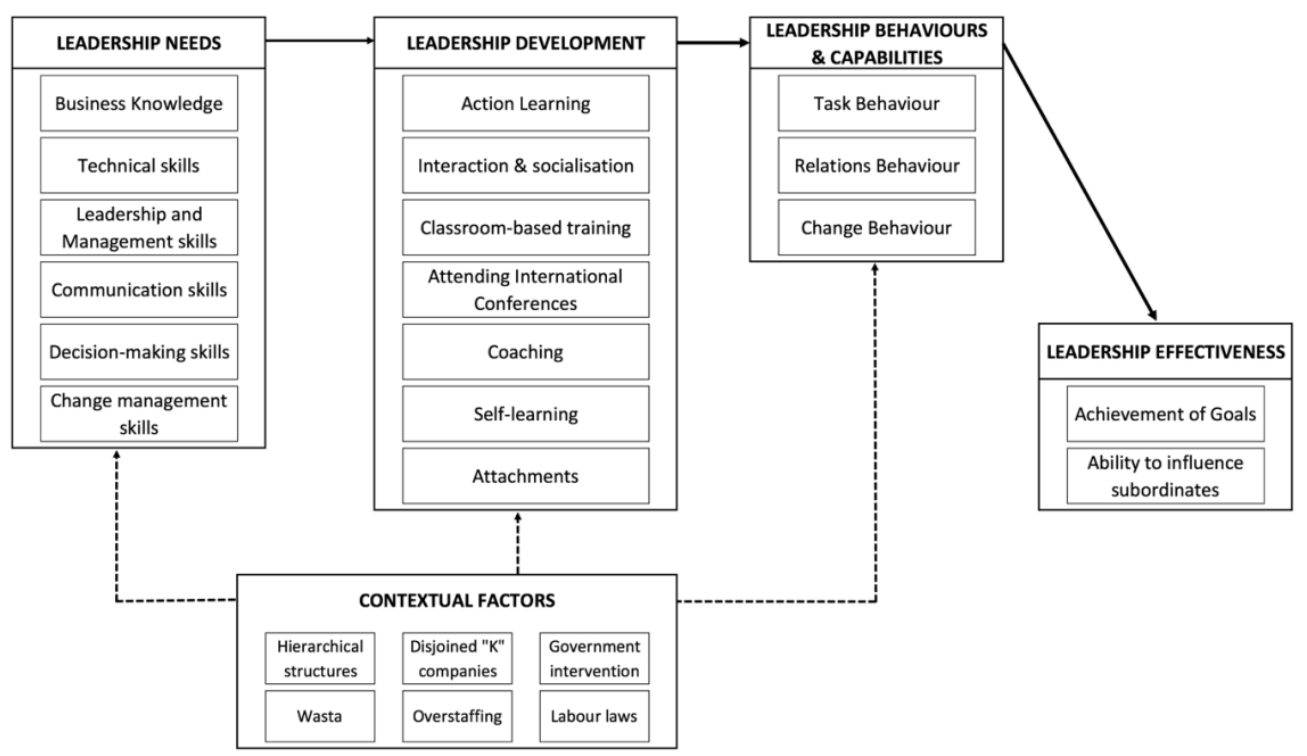

\section{References}

Bolden, R. (2005). The face of true leadership, European Business Forum, 21, 54-57.

Bolden, R. and Gosling, J. (2006). Leadership competences: time to change tune. Leadership,2(2), 147-64.

Bolden, R. (2010). Leadership, Management and Organisational Development. Centre for Leadership Studies, University of Exeter, UK.

Bolden, R. (2011) Distributed Leadership in Organizations: A Review of Theory and Research, International Journal of Management Reviews, 13, 251-269

Burgoyne, J., Hirsh, W. and Williams, S. (2004). The Development of Management and Leadership Capability and its Contribution to Performance: The evidence, the prospects and the research need. DFES Research Report 560, London: DFES.

Clarke. N. (2012). Evaluating Leadership Training and Development: A Levels-of-Analysis Perspective. Human Resource Development Quarterly. 23(4), 441-460.

Cohen, L., and Manion, L. (1994). Research methods in education (4th ed.). London: Routledge.

Creswell, J. (2003) Research design: Qualitative, quantitative and mixed methods approaches. Thousand Oaks: Sage Publications.

DeChurch, L. A., Hiller, N. J., Murase, T., Doty, D. and Salas, E. (2010). Leadership across levels: Levels of leaders and their levels of impact. The Leadership Quarterly, 21(6), 1069-1085.

Friedrich, T. L., Vessey, W. B., Schuelke, M. J., Ruark, G. A. and Mumford, M. D. (2009). A framework for understanding collective leadership: The selective utilization of leader and team expertise within networks. The Leadership Quarterly, 20, 933-958.

Gronn, P. (2002). Distributed leadership as a unit of analysis. The Leadership Quarterly, 13, 423-451.

House, R. J., Hanges, P. J., Javidan, M., Dorfman, P.W., and Gupta, V. (2004). Culture, leadership and organisations:The GLOBE study of 62 societies. London, UK: SAGE

Johnson, I. J and Cacioppe, R. (2012). Leader/ship development: Moving in place or moving forward: A review of theories, methods and effectiveness of leader/ship development. March 2012.

Mameli, P. (2013) Under New Management: What the Arab Spring Tells Us About Leadership Needs in the Middle East and North Africa. Digest of Middle East Studies, 22(2), 377-404.

Mertens, D. M. (2005). Research and Evaluation in Education and Psychology: Integrating Diversity with Quantitative, Qualitative, and Mixed Methods, Thousand Oaks, CA: Sage Publications.

Northouse, P. G. (2013), Leadership: Theory and practice, Los Angeles, CA: Sage Publications.

Okoji, O. O (2014). Influence of Leadership Styles on Community Development Programmes' Implementation in Rural Communities of Akwa Ibom State Nigeria. An International Multidisciplinary Journal, Ethiopia, $8(2), 83-95$

Overby, J., and Suvanujasiri, A. (2012). Confirmatory Factor Analysis of a Leadership Competency Model: An Empirical Study Conducted in Thailand. Journal of Applied Business Research, 28(5), 1073-1084

Sadeghi, A. and Pihie, L. A. Z (2012). Transformational Leadership and Its Predictive Effects on Leadership Effectiveness. International Journal of Business and Social Science, 3(7), 186-197.

Senge, P. (2006) The fifth discipline: The Art and Practice of the Learning Organization, Century, London. 
Sosik, J. J. and Dinger, S. L. (2007) Relationships between leadership style and vision content: The moderating role of need for social approval, self-monitoring, and need for social power. Leadership Quarterly. 18(2), 134153.

Thorpe, R., Gold, J., and Lawler, J. (2011) Locating Distributed Leadership, International Journal of Management Reviews, 13(2011), 239-250

Yukl, G. (2013). Leadership in Organizations. Eight Edition. Upper Saddle River, N.J: Pearson Education. 